\title{
Geochemistry of Surface Waters Around Four Hard-Rock Lithium Deposits in Central Europe
}

\author{
JONAS TOUPAL AND RETO GIERÉ
}

University of Pennsylvania

Presenting Author: toupal@sas.upenn.edu

The European Union is working hard to transition to a lowcarbon, secure, and competitive economy [1]. Part of the effort involves creating a lithium supply chain from mining to electric vehicle manufacturing within the continent. There are several Ligranite and pegmatite deposits in Central Europe. The Cínovec deposit on the border between the Czech Republic (CZE) and Germany (GER) is being actively explored, as it is the largest $\mathrm{Li}$ hard-rock deposit in Europe [2]. Little is known about aqueous geochemistry near lithium hard-rock deposits [3]. Lithium is used in medicine to treat bipolar disorder, but is known to cause serious side effects (e.g., renal failure, diziness, poor memory [4]). The EPA recommends a Li limit for drinking water of 0.7 ppm [5]. Li-micas are additionally rich in fluorine. Fluoride in drinking water is one of ten elements of concern identified by the WHO, known to cause fluorosis above $1.5 \mathrm{ppm}$ [6].

In this study, we sampled surface waters $(n=47)$ from creeks and rivers near three Li-mica and one spodumene deposit to examine whether or not the weathering of Li-minerals could lead to a potential public health risk in the surroundning areas. In the Cínovec (CZE/GER) and Homolka (CZE) deposits, several water samples are elevated (max of $36 \mathrm{ppb}$ ) relative to typical $\mathrm{Li}$ concentrations (1-20 ppb [7]) in surface waters, but they do not surpass the EPA-recommended threshold. Three of the ten samples from the Cínovec deposit are above WHO's $1.5 \mathrm{ppm}$ drinking water limit for $\mathrm{F}$ ( $\max$ of $3.806 \mathrm{ppm}$ ) and may pose a public health hazard. Based on geochemical inverse modeling in PHREEQC, both $\mathrm{Li}^{+}$and $\mathrm{F}^{-}$are derived from the Li-micas, but most of the $\mathrm{F}^{-}$comes from fluorite, present in minor amounts in the original host rocks.

[1] Lebedeva et al., (2017) EC Report JRC105010. [2] Gourcerol et al., (2019) Ore Geol. Rev.109, 494-519. [3] Bradleyet al., (2017) USGS Report2010-5070-0. [4] Mayo Clinic (accessed 1/2021) Lithium (Oral Route) [5] Tripathi, (2011) Virginia Department of Health, accessed 1/2021. [6] WHO, (1999) Geneva, Switzerland, accessed 1/2021.[7] Kavanagh et al., (2018) Resources 7, 57, 1-29. 